\begin{tabular}{ccc}
\hline International Journal of Health Services \\
Research and Policy \\
www.dergipark.org.trijhsrp \\
INESEG \\
INTERNATIONAL \\
ENGINEERING \\
EDUCATION AND
\end{tabular}

Research Article

\title{
QUALITATIVE ANALYSIS OF THE INFORMATION OF HEALTHCARE PROFESSIONALS WORKING IN PEDIATRICS UNITS ON CHILDREN'S RIGHTS
}

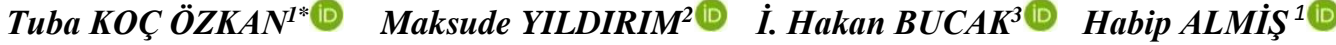

\author{
${ }^{1}$ Adıyaman University Faculty of Health Sciences, Midwifery Department, Adıyaman, Turkey \\ ${ }^{2}$ Inonu University Faculty of Nursing, Child Health and Disease Nursing Department, Malatya, Turkey \\ ${ }^{3}$ Adıyaman University Faculty of Medicine, Department of Child Health and Diseases, Adiyaman, Turkey \\ *Corresponding author; tubakocozkan@gmail.com
}

\begin{abstract}
It is important for health professionals working with children to be aware of all aspects of children's rights. the study was conducted to determine the qualitative analysis of the knowledge of the healthcare professionals working in pediatrics units on children's rights. Twenty health workers in the pediatric units of an obstetric and children's hospital, nine physicians and eleven nurses, took part in the research. Data were collected with the semi-structured interview technique using an 'information form' and a 'structured interview form'. Data were then subjected to analysis. Two themes were determined as "the views of healthcare professionals on children's rights" and "what can be done to better implement children's rights". In line with these themes; it was determined that healthcare workers mostly focused on children's right to life and development, and other rights were not mentioned much. It was determined that healthcare professionals thought that training should be given to raise awareness of children's rights. It is recommended that in-service training be provided to increase the knowledge and awareness of children's rights among health workers in pediatric units.
\end{abstract}

Keywords: Child, Children's Rights, Nurse, Physician

Received: November 24, $2020 \quad$ Accepted: April 01, 2021

\section{Introduction}

Right is the authority granted to individuals by legal rules and the legal order where laws are valid $[1,2]$. Human rights, on the other hand, are generally expressed as rights that people have simply because they are human. There is a basis of equality in human rights rules, it is universal. Therefore, it has high moral quality [3,4]. The purpose of human rights is to ensure the development of innate and only human qualities. It is within the scope of inalienable and non-assignable rights. Human rights are rights that require respect everywhere and in any situation [5]. Patient rights are the implementation of basic human rights in health services. Patient rights refer to the rights of individuals who need to benefit from health services, which are guaranteed by International Conventions, Constitution of Turkey, Law, and other legislation. The first official statement on patient rights is the Nuremberg Laws. The Nuremberg Laws impose the responsibility of informing the patient and obtaining his consent before the procedure is 
performed. Many international declarations have been conducted on patient rights. "Declaration of Helsinki" published in 1963, "Declaration of Lisbon Patient Rights" published by the World Medical Association in 1981, "Declaration on the Improvement of Patient Rights in Europe" published in Amsterdam in 1994 and The "Bali Declaration" published by the World Medical Association in 1995 is among the most important studies in the field of patient rights [6,7]. Turkey also in the light of these developments, in 1998, prepared by the Ministry of Health, "Patient Rights Regulation" was published [5].

Patient rights are defined as a set of rules that all personnel in the health system should apply and pay attention. In order to implement the rules, to provide the best health service, and to prevent violations of rights; healthcare professionals should provide patients with a friendly, respectful, and reliable health service [8].

With the development of patient rights, children's rights are also an issue that has come to the fore again [9]. The United Nations Convention on the Rights of the Child, published in 1989, has special importance for children's rights. This Convention is the first tool developed to cover all international human rights that concern children only. This contract is part of almost all countries throughout the world, Turkey has started to implement it on September 14, 1995. The Convention has four guiding principles and these principles are essential requirements for the fulfillment of all children's rights. These principles are categorized under four main groups: non-discrimination, the best interests of the child, the right to life, survival, and development, and the right to respect the views of the child [10,11]. All rights specified in the United Nations Convention on the Rights of the Child, published in 1989, should also be implemented in health services [12]. Children have the right to be informed about the disease and treatment according to their age and developmental period. Children have the right to participate in any decision concerning their health condition. Every child has the right to be protected from unnecessary medical treatment and examinations. Children have the right to be in an environment suitable for their age and situation, with extensive opportunities for play, rest, and education. The environment should be arranged in a way that suits the needs of the children and should have appropriate personnel. Their education and empathy skills have the right to be cared for by health personnel who can respond to the physical, mental, and developmental needs of children and the needs of their families. Children should be approached with feelings and understanding, and they have the right to respect their privacy at all times. Every child has the right to be protected from unnecessary medical treatment and examinations [13].

Healthcare professionals have to take children's rights into consideration while protecting and improving the health and well-being of children. In this context, showing attitudes and behaviors in accordance with the Convention on the Rights of the Child, such as ensuring the participation of the child in the decision and treatment process and paying attention to the privacy of the child, increase compliance with treatment, while wrong behaviors against the rights of the child may negatively affect the physical and psychological health of the child. Knowing the extent to which the rights of hospitalized children are actually respected by healthcare professionals is essential for the implementation of children's rights and for planning measures to guarantee their psychological and physical health in the hospital. However, Bisogni et al. (2015) reported significant variations regarding the application of children's rights among different regions of Italy, and even among children's hospitals and general hospital pediatric units [14]. Kahriman et al. (2016) studied the thoughts of midwives and nurses who provide health services to the pediatric age group on the rights of children. In the study, it is seen that 
midwives and nurses do not agree on the problems encountered in clinical practices regarding children's rights [9]. There are a limited number of studies in the literature that examine healthcare professionals' awareness of children's rights [14-19]. For this reason, discussing the thoughts and opinions of children's rights of healthcare personnel, especially on scientific platforms can provide significant contributions.

\section{Materials and Methods}

\subsection{Research Aim and Type}

The research was performed to determine healthcare professionals' perceptions concerning children's rights. A phenomenological approach, in a qualitative research design, was employed. The phenomenological approach examines subjects on which awareness is present, but not deep and detailed knowledge. At the same time, phenomenology focuses on revealing the individual's experiences and perceptions regarding a particular phenomenon or event [20,21].

\subsection{Time and Place of the Research}

The research was carried out in the pediatric clinics of an Obstetric and Children's Hospital in a province in Southeast Turkey between 1 July 2018, and 1 July 2019.

\subsection{Research Population and Sample}

The research was conducted with physicians and nurses working in an Obstetrics and Children's Hospital. Physicians and nurses providing health services for pediatric patients were included in the research. Detailed interviews are usually performed in phenomenological approaches, and small groups are generally reported to be sufficient [22]. At the same time, data obtained when the saturation point is reached are also reported to be sufficient $[23,24]$. Interviews were concluded when data began to be repeated. The research was conducted with 20 health workers ( 9 physicians and 11 nurses).

\subsection{Data Collection Tools}

Data were collected using an information form and structured interview form involving health workers' descriptive characteristics.

The information form contained five questions concerning health workers' socio-demographic characteristics, such as sex, occupation, marital status, whether they had children, and professional experience. In phenomenological approaches, data can be collected from individuals experiencing an event using several methods, including artistic products, keeping a diary, reflection reports, artistic content reflecting experience, and observation. The most commonly employed method is in-depth interviews or focuses group interviews [25].

A semi-structured interview form was used in this research to determine participants' perceptions regarding children's rights. The form was prepared by the authors based on the previous literature [2628]. A preliminary application was performed with three health workers before the study began. The data obtained from these interviews were not included in the research. The questions on the structured interview form were as follows:

- What kind of rights do children have? To what extent do you think children are aware of their rights? What can be done to raise their awareness? 
- Do you think there are any rights that children cannot benefit from? If you think there are rights that children cannot use, which are these, and why cannot they benefit from them?

- What responsibilities do you think health workers have in the implementation of children's rights?

- What do you think can be done in the hospital regarding the better implementation of children's rights?

\subsection{Performance of the Research}

The research data were collected using the in-depth interview method with healthcare professionals. The place and time of the meeting were determined by establishing communication with each participant before the interview. In the preliminary interview, participants were informed about the scope and objectives of the research. Face-to-face interviews were held whenever the participants were appropriate for the study. Participants were informed that they could leave whenever they wanted and were free to answer any questions they wanted. Interviews were held in a quiet room in the hospital, with the interviewer sitting opposite the healthcare professionals and at the same level. All face-to-face interviews were conducted by a researcher. Voice recordings were taken during the interviews, with prior permission. Interviews lasted approximately 20-30 min.

\subsection{Statistical}

The quantitative data were evaluated using the SPSS 21.0 package program. Descriptive statistical methods (percentage, arithmetic mean) were used in the study. The qualitative data obtained in the research were analyzed and interpreted using the 'content analysis' method. The content analysis aims to elicit relations and concepts capable of explaining data. Within that context, data were analyzed in four stages - data coding, themes, the arrangement of data by codes and themes, and definition [20,29].

In the first stage, the interviews that were recorded on audio were recorded on paper. In the next step, the raw data obtained was carefully read by each researcher, and in this way, the whole data was tried to be dominated. Then, using content analysis, the coding of the data was carried out by each author separately. After this process, the themes, categories, and codes produced by each author were brought together; As a result of the examination of similarities and differences, the final theme, category, and codes were created. The opinions of the participants were conveyed by coding on the basis of confidentiality, without giving their names. Accordingly, the participants were coded as "HP" to denote "health professionals" and each participant was given numbers such as HP1, HP2, HP3 ... in addition to their code. Two themes were thus established with the combined codes:

Theme 1. Health Workers' Opinions on the Subject of Children's Rights

Theme 2. What Can Be Done to Improve the Implementation of Children's Rights?

\section{Ethical Considerations}

Ethical committee for the research was obtained before commencement from the NonInterventional Clinical Research Ethical Committee of the Adiyaman University (date:26.06.2018/decision no. 2018/5-19). Verbal and written consent was also obtained from health workers agreeing to take part. The identities of the health workers were concealed during the reporting of the research, with numbers being used instead of names. The research was conducted in accordance with the Declaration of Helsinki. 


\section{Results}

Nine physicians and 11 nurses took part in the study. The mean age of the health workers was $33.00 \pm 4.14$ years.

Seventy percent were women, $65 \%$ were single, $70 \%$ had children, and $75 \%$ had professional experience greater than five years (Table 1).

Table 1. Health workers' sociodemographic characteristics

\begin{tabular}{lcc}
\hline Sociodemographic characteristics & \multicolumn{2}{c}{ Mean \pm SD } \\
\hline Age & n & \% \\
\hline & & \\
\hline Sex & 14 & 70 \\
\hline Female & 6 & 30 \\
Male & & \\
\hline Occupation & 9 & 49 \\
$\quad$ Physician & 11 & 51 \\
$\quad$ Nurse & & \\
\hline Marital status & 7 & 35 \\
\hline Married & 13 & 65 \\
$\quad$ Single & & \\
\hline Children & 14 & 70 \\
$\quad$ Yes & 6 & 30 \\
$\quad$ No & & \\
\hline Professional experience & 5 & 25 \\
\hline 0-5 years & 15 & 75 \\
$\quad$ More than 5 years &
\end{tabular}

Two themes were determined in the research - 'health workers' opinions on the subject of children's rights,' and 'what can be done to improve the implementation of children's rights?'

\section{Theme 1. Health Workers' Opinions on the Subject of Children's Rights}

This section consisted of two sub-themes, awareness of children's rights, and the situation concerning benefitting from children's rights.

This section consists of two sub-themes: statements of healthcare professionals about what children's rights are, children's awareness of children's rights, and the state of enjoying children's rights.

\section{Sub-theme 1: Statements and awareness of Children's Rights}

When healthcare professionals are asked what children's rights are; most of the participants stated that children have the right to education, health, and life. The great majority of health workers reported that children were unaware of their rights. They suggested such measures as provision of education, public service announcements, educating families, and allowing children to express themselves in order to increase awareness. Specimen comments are shown below:

"HP 2: They have rights to education, health, and play. Due to a lack of paternal awareness in our society, with its inadequate education levels, children are unaware they have rights in the world into which they are born."

"HP 4: They have rights to life, health, and education. Children are not aware of their rights. A level of awareness, therefore, needs to be created. Lessons could be given in school.

"HP 6: Children need to be protected. Children have the right to care under suitable conditions, to play, and to education. Children are not at all aware of their rights. We must allow them the right to express themselves so they can acquire awareness." 
"HP 10: Children have rights to education, teaching, shelter, protection, and health services. Children can be made aware of their rights through education, and the majority of children are not aware of all their rights."

"HP 13: They have the right to love and be loved, to be valued, to raise objections, and to complain of violence. Children's awareness of their rights varies depending on their age, place of residence, and the family's financial means. Families have to be educated first, then children can be shown educational material or visual aids explaining their rights, in kindergartens or schools, and if necessary in a health clinic in villages."

"HP 16: They have the right to shelter, life, food, and education. Children are not aware of their rights. In order for them to be aware of these rights, families have to be educated first, and families need to be informed, depending on their sociocultural levels."

\section{Sub-theme 2: Children's Ability to Benefit from Children's Rights}

Health workers stated that children were unable to benefit from such rights as shelter, education, nourishment, and play for reasons including financial difficulties, parents being at work, prolonged duration of education, and children being unaware of their own rights. Some specimen comments are given below:

"HP 2: They may be unable to enjoy their rights to education, health, and spending sufficient time with their families. They may be unable to benefit from their rights in Turkish society, with its low socioeconomic and education levels."

"HP 3: They may not enjoy their rights due to families having insufficient financial or psychological resources."

"HP 6: In my opinion, children are unable to benefit from their right to play, because educational activities are very lengthy and their families are always working."

"HP 9: They cannot benefit sufficiently from their rights to education, play and nutrition because of financial difficulties."

"HP 11: There are rights they cannot benefit from. Not everyone can study under equal conditions. The majority of children work out in the fields from early ages, or girls are married off early."

"HP 12: The right to education cannot be equally applied in all regions of Turkey. This derives from families' lack of awareness."

"HP 13: Yes, there are rights they cannot benefit from. A child does not know that he has the right to complain when violence is inflicted by his family, or else he cannot enforce that right, because older relatives think that will be disrespectful."

\section{Theme 2. What Can Be Done to Improve the Implementation of Children's Rights?}

This theme was examined under two sub-themes, 'health workers' responsibilities toward children's rights,' and 'measures that can be taken concerning children's rights in hospital.'

\section{Sub-theme 1: Health Workers' Responsibilities toward Children's Rights}

Health workers made recommendations for the better implementation of children's rights, such as education, encouraging family planning, and raising parental and child awareness on the subject of children's rights. Some comments are given below:

"HP 13: Healthcare professionals must observe every child they encounter and must teach as many parents and children as possible." 
"HP 17: Responsibilities in the context of health must be explained, and families must be informed about children's rights. The relevant authorities must be informed if children's rights are suspected of being violated."

"HP 20: Mothers and fathers must be given education, and must be informed about children's rights before the child is born."

\section{Sub-theme 2: Measures that can be Taken Concerning Children's Rights in Hospitals}

Healthcare professionals stated that in order for better use to be made of children's rights, training regarding those rights could be provided in the hospital, child play areas might be expanded, and environments might be established in which children could stay with their families in hospital:

"HP 1: Education might be provided through awareness meetings, posters, presentations, and written material."

"HP 5: A large children's play area should be constructed. Wards should be sufficiently large and have sufficient capacity for children scheduled for admission."

"HP 6: Play areas for children could be created on the wards, and they must be able to stay with their families on the wards."

"HP 10: There should be an exchange of information at every meeting with children. The poster could be put up in hospitals for awareness purposes."

"HP 13: Posters could be put up in hospital entrances, cartoons explaining children's rights could be shown, and training could be provided for families.

\section{Discussion}

In order to ensure that children benefit from children's rights, it is important that healthcare personnel are aware of children's rights and provide health services accordingly. It is known that being educated and informed about children's rights positively affects attitudes towards children's rights $[15,30]$. According to the results of this study, healthcare professionals did not fully express children's rights. In the study conducted by Öztürk et al. (2018) to determine the knowledge levels of health services vocational school students on patient and child rights, it was determined that students who have knowledge about child and patient rights are more sensitive to these issues [16]. In the study in which Küçük Alemdar and Y1lmaz (2019) examined the attitudes of pediatric nurses towards children's rights, the nurses were asked whether they had information about children's rights. The majority of the nurses stated that they have information about children's rights. It has been reported that nurses who are knowledgeable about children's rights show a positive attitude towards children's rights [15]. In the study in which Ergin et al. (2020) examined the knowledge, attitudes, and behaviors of physicians on children's rights, it was determined that half of the physicians do not know the Convention on the Rights of the Child, and physicians who do not know the contract show negative attitudes and behaviors towards children's rights [17]. Similar to the literature, it was found in the study that healthcare professionals did not have sufficient information about children's rights. For this reason, it can be said that healthcare professionals are partially informed about children's rights.

In the United Nations Convention on the Rights of the Child, children's rights are included in four main principles as non-discrimination, the best interests of the child, the right to life, survival, and development, and the right to respect the views of the child [10,11]. The Convention on the Rights of the Child guarantees all developmental areas of the child. The Convention on the Rights of the Child 
guarantees all developmental areas of the child. In this study, health professionals stated that children have the right to education, health, and life, but did not emphasize the right to respect the views of the child. The studies show that there are still deficiencies for children to fully benefit from their rights. Research conducted among European countries has shown that children's participation in decisionmaking is weak [31]. In the study conducted by Bisogni et al. (2015) on the implementation of sick child rights in pediatrics units in Italy, nurses reported that the most common right of children to be with their parents and to play is the right of the child to express himself or herself [14]. In this study, it was determined that healthcare professionals did not mention the right to respect the views of the child, such as expressing their own views and participating in decisions on matters that concern them. This situation may negatively affect the attitudes, behaviors, and healthcare practices of healthcare professionals towards children's rights. For this reason, if healthcare professionals learn about children's rights in all aspects, they can also protect children's rights in health services provision.

It is very important for children to be aware of their rights and to be able to internalize them. Knowing only some of their rights can cause children to violate one right while exercising another. For example, when children exercise their right to play and recreation, they themselves may violate the right to protection, the right to self-expression, or the right to education. Therefore, children also need to know all children's rights [26,32]. In the study conducted by Küçük Alemdar and Yılmaz (2019), nurses stated that children were not raised enough about children's rights [15]. Similar to the study of Küçük Alemdar and Y1lmaz, the majority of the healthcare professionals stated that the children were not aware of their rights. There are studies in the literature that show that children do not have sufficient information about children's rights [26, 33,34]. The awareness of healthcare professionals about children's lack of knowledge on this subject can lead to their educational and advocacy roles for children.

The environment in which they socialize has an effect on the knowledge of children's rights. In this context, different economic, socio-cultural environments, the perspective of the child, and the implementation of children's rights affect the state of knowledge about children's rights. In different studies, it has been reported that factors such as the parents' age, education level, and economic status affect children's awareness of their rights $[27,35,36]$. In the study, healthcare professionals stated that socio-demographic characteristics such as age, place of residence, and economic situation affect children's awareness of their rights and that family and child education about children's rights is necessary. It can be thought that healthcare professionals are aware of this situation and will implement children's rights and provide consultancy by taking this situation into consideration in the provision of health services to children.

The World Health Organization (2017) states that every child in the hospital should have the right to respect the views in healthcare decisions that affect them and to receive information [37]. The child and parents should be informed according to their age and understanding [38]. Health professionals serving the pediatric age group have the responsibility of informing the child and family about children's rights and supporting the family, implementing children's rights within the health system, and defending children's rights [13]. In this study, health professionals mostly stated that children and families should be educated about children's rights and children should be protected in cases of abuse. In addition, they stated that in order to better implement children's rights, children and families can be informed about children's rights with posters and televisions in the hospital environment, children's playgrounds can be expanded, and environments, where children can stay with their families in the hospital, can be created. In line with these results, it can be said that healthcare professionals are aware of their responsibilities 
in terms of children's rights. In their study, Fernandes Guerreiro (2014) found that attention has not cared to children's right to play and learning in the hospital [18]. In the study of Bisogni et al. (2015), it was reported that there are deficiencies in the implementation of the rights of hospitalized children in pediatric units according to the perception of pediatric nurses [14]. In the study of Schalkers et al. (2016), it was found that healthcare professionals thought that children were not active participants in health services [19].

\section{Conclusion}

This research, performed in order to determine healthcare professionals' perceptions regarding children's rights, revealed that although healthcare professionals had some knowledge of those rights, particularly the rights to life and development, they require greater awareness of how children's rights can be implemented within the hospital environment. In addition, the fact that healthcare professionals do not mention the right to respect the views of the child shows there is a serious need for education on that subject. In the light of our findings, we recommend that classes involving children's rights be included in the curricula of students in the field of medicine and health.

The awareness of children's rights among healthcare professionals serving the pediatric age group can also be raised through in-service seminars. Due to the lack of sufficient studies concerning children's rights in the literature, we recommend that particular priority be attached to these. Healthcare professionals' awareness of children's rights can thus be increased, and procedures during diagnosis, treatment, and care can thus be performed with a focus on the rights of the child.

The Compliance to the Research and Publication Ethics: This study was carried out in accordance with the rules of research and publication ethics.

Ethics Committee Approval: Ethical committee for the research was obtained before commencement from the Non-Interventional Clinical Research Ethical Committee of the Adiyaman University (date:26.06.2018/decision no. 2018/5-19).

Informed Consent: The health workers participating in the research informed about their consent were received in writing.

Author Contributions: Study design: T.KÖ, H.B, M.Y; Data collection: H.B; Data analysis: T.KÖ;

Manuscript preparation: T.KÖ, H.B, H.A

Acknowledgments: The authors thank those who participated in this study.

Conflict of Interest: There is no conflict of interest in this research.

Financial Disclosure: There are no financial supports.

Statements: This study has not been presented in any meeting.

\section{References}

[1] Brysk, A., The Future of Human Rights, Clays Ltd., United Kingdom, 2018.

[2] Ministry of National Education. Health Services Secretariat, Patient Rights I, http://megep.meb.gov.tr/mte_program_modul/moduller_pdf/Hasta\%20Haklar\%C4\%B1\%201.p $\underline{\mathrm{df}}$ 
[3] Turhan, A., "Complementarity relations between human rights generations", Inönü University Faculty of Law Journal. 4(2), 357-378, 2013.

[4] Soykan, C., "Refugee and Human Rights", Kontras Journal, 45(1), 4-7, 2015.

[5] Firat, A., "Turkey patient rights and responsibilities in the health business", Istanbul Gelişim University Journal of Health Sciences, 2(2), 157-173, 2017.

[6] Taylan, H.H., Baydoğan, T., 'Investigation of patients' and their relatives' level of knowledge and their utilization situation regarding the patient rights and "patient rights unit", Electronic Journal of Social Sciences, 14(55), 248-256, 2015.

[7] Karakılıç, Ü., "Patient rights", Aydın Provincial Health Directorate Digital Health Journal, 2020(2), 39-45, 2020.

[8] Soysal, A., Mahanoğlu, E., "Determination of attitudes of patients using patient rights: a survey in primary health care institution: (case of Hatay province)", Journal of Süleyman Demirel University Institute of Social Sciences, 1(30), 138-158, 2018.

[9] Kahriman, İ., et al., “Thoughts about child patients' rights”, Health Sciences Journal, 5(1), 1829, 2016.

[10] Akyüz, E., Çocuk Hukuku (Children's Law), Pegem Academy, Ankara, 2012.

[11] Şener-Taplak, A., et al., "Children's rights omissions and solutions", Erciyes University Journal of Health Sciences, 2(1), 62-71, 2014.

[12] Donnelly, M., Kilkelly, U., "Child-friendly healthcare: delivering on the right to be heard", Medical Law Review, 19(1), 27-54, 2011.

[13] Cilar, L., et al., Children's rights in hospital: a literature review, in: Compendium of Contemporary Legal Issues (Ed. S. Kraljić, Y. Ünver), University of Maribor Press, Slovenia, pp. 123-135, 2019.

[14] Bisogni, S., et al., "Actual implementation of sick children's rights in Italian pediatric units: a descriptive study based on nurses' perceptions", BMC Medical Ethics, 16(33), 1-8, 2015.

[15] Küçük-Alemdar, D., Y1lmaz, G., "Determination of attitudes of pediatric nurses towards children's rights", Celal Bayar University Journal of Health Sciences Institute, 6(2), 121-126, 2019.

[16] Öztürk, H., et al., "Determination of the knowledge levels of patient and child rights of health services vocational school students" The Journal of Kesit Academy, 4(15), 274-281, 2018.

[17] Ergin, A., et al., "Knowledge, attitudes and behaviors of medical residents and interns about children's rights", Pam Medical Journal, 13(2), 303-310, 2020.

[18] Fernandes-Guerreiro, A.I., "Assessing the respect of children's rights in hospitals in Kyrgyzstan and Tajikistan, WHO project: Improving the quality of pediatric care in the first level referral hospitals in selected countries of Central Asia, 2014 http://www.euro.who.int/_data/assets/pdf_file/0020/252542/Assessing-the-respect-ofchildrens-rights-in-hospitals-in-Kyrgyzstan-and-TajikistanEng.pdf?ua=1 
[19] Schalkers, I., et al., "Health professionals' perspectives on children's and young people's participation in health care: a qualitative multihospital study", Journal of Clinical Nursing, 25(7-8), 1035-1044, 2016.

[20] Tanyaş, B., "Introduction to qualitative research methods: General principles and their applications in psychology", Critical Psychology Bulletin, 5(1), 25-38, 2014.

[21] Baltac1, A., "A conceptual review of sampling methods and sample size problems in qualitative research", Journal of Bitlis Eren University Institute of Social Sciences, 7(1), 231-274, 2018.

[22] Polit, D.F., Beck, C.T. Essentials of Nursing Research: Appraising Evidence for Nursing Practice, Lippincott Williams \& Wilkins Inc., Philadelphia, pp. 267-268, 2010.

[23] Blanche, M.T., et al., Research in Practice: Applied Methods for the Social Sciences, Juta and Company Ltd., South Africa, 2006.

[24] Elo, S., Kyngäs, H., "The qualitative content analysis process", Journal of Advanced Nursing; 62(1), 107-115, 2008.

[25] Çekmez, E., "Phenomenographic research method", Necatibey Faculty of Education Electronic Journal of Science and Mathematics Education, 6(2), 77-102, 2012.

[26] Ersoy, A.F., “Elementary school students' perceptions related to children's rights”, Elementary Education Online, 10(1), 20-39, 2011.

[27] Ersoy, A.F., "An area neglected in citizenship education: children's rights education at home and at school", International Online Journal of Educational Sciences, 4(2), 359-376, 2012.

[28] Leblebici, H., Çeliköz, N., "Prospective teachers' attitudes towards children's rights", International Journal of Social Sciences and Education Research, 3(1), 307-318, 2017.

[29] Holloway, I., Galvin, K., Qualitative Research in Nursing and Healthcare, John Wiley \& Sons, United Kingdom, 2016.

[30] Karaman-Kepenekçi, Y., Baydık, B. "The attitudes of the mentally handicapped teacher candidates regarding children's rights", Ankara University Journal of Educational Sciences, 42(1), 329- 350.

[31] Ehrich, J.H.H., et al., "Participation of European children in medicine", Pädiatrie \& Pädologie, 49(supp1), 19-24, 2014.

[32] Seyhan, G.B., Cansever, B.A., "Examining teacher candidates' child rights perception within material designs and thoughts", Mehmet Akif Ersoy University Journal of Education Faculty, 1(41), 98-119, 2017.

[33] Uçuş, Ş., "Exploring children's perceptions and metaphors on children's rights", Ahi Evran University Journal of Kırşehir Education Faculty 2016; 17(3), 811-833.

[34] Hareket, E., Yel, S., "Which perceptions do we have related to our rights as a child? Child rights from the perspective of primary school students", Journal of Education and Learning, 6(3), 340-349, 2017. 
[35] Tatl1, S., et al., "The investigation of the child-rearing attitudes and family lives of the mothers whose children continue their pre-school education", Bingöl University Journal of Social Sciences Institute, 2(3), 101-114, 2012.

[36] Kızılırmak, K., Ersoy, Ö.A., "Investigation of the attitudes of mothers of children attending primary school to the rights of children (Ankara sample))", Hacettepe University Faculty of Health Sciences Journal, 1(2), 523-541, 2015.

[37] WHO, (2017). Children's rights in hospital: Rapid-assessment checklists [Online],http://www.euro.who.int/ data/assets/pdf file/0004/342769/Check-listChild-rightsin-hospital_layoutOPE.pdf

[38] EACH (2016) The EACH Charter with Annotations. https://docs.google.com/viewer?url=https\%3A\%2F\%2Fwww.each-forsickchildren.org\%2Fimages\%2Fstories\%2F2016\%2FCharter AUG2016 oSz.pdf 